\title{
RADIAÇÃO GAMA NA CONSERVAÇÃO DE CARNE: UMA REVISÃO
}

\section{RADIATION IN MEAT CONSERVATION: A REVIEW}

\author{
F. R. PASSOS ${ }^{1}$, F. Q. MENDES ${ }^{1}$ \\ Universidade Federal de Viçosa \\ Campus Rio Paranaíba \\ E-mail: flaviapassos1@yahoo.com.br
}

\author{
article info \\ Article history: \\ Received 12 May 2017 \\ Accepted 3 August 2017 \\ Available online 20 September 2017
}

PALAVRAS-CHAVE: Irradiação: Segurança alimentar; Vida útil.

\author{
KEYWORDS: Irradiation; Food safety; Shelf Life.
}

RESUMO: $O$ desejo de garantir a segurança alimentar para consumo requer melhores técnicas de conservação de alimentos. A irradiação é considerada um dos processos tecnológicos mais eficientes para a redução de microrganismos em alimentos. Nesta revisão de literatura sobre a radiação gama foram abordadas pesquisas realizadas no setor de cárneos. São apresentados os resultados de avaliações efetuadas com o objetivo de reduzir microrganismos patogênicos e identificar as alterações físico-químicas e sensoriais ocorridas pela interação ionizante com o alimento irradiado, visando prolongar a vida útil da carne. Embora a irradiação de alimentos constitua tema desconhecido para a maioria da população brasileira, o processo é seguro e não oferece risco ao consumidor e nem ao meio ambiente, pois não produz nenhum tipo de resíduo. $O$ uso da técnica de irradiação para a conservação de carne, por si só, não soluciona todos os problemas de deterioração, devendo-se preservar o alimento em condições assépticas após irradiado, evitando assim nova contaminação.

\begin{abstract}
The desire to ensure food security for consumption requires better techniques of food conservation. Irradiation is considered one of the most efficient technological processes for the reduction of microorganisms in foods. In this review of the literature on gamma radiation, studies were carried out in the meat industry. The results of evaluations carried out with the objective of reducing pathogenic microorganisms and identifying the physicochemical and sensorial changes occurring by the ionizing interaction with the irradiated food, aiming to prolong the shelf life of the meat are presented. Although food irradiation is an unknown issue for most of the Brazilian population, the process is safe and offers no risk to the consumer or the environment, as it does not produce any type of residue. The use of the irradiation technique for meat preservation alone does not solve all problems of deterioration, and the food should be preserved in aseptic conditions after irradiation, thus avoiding new contamination.
\end{abstract}

\section{INTRODUÇÃO}

A carne é um alimento extremamente rico em proteínas, gordura e sais minerais e com elevado teor de umidade. Estas características a tornam um produto propício ao desenvolvimento de microrganismos patogênicos, caso a mesma não seja conservada 


\section{The Journal of Engineering and Exact Sciences - \\ JCEC \\ ISSN: 2527-1075}

adequadamente e manipulada em condições rígidas de limpeza do local e do próprio manipulador (GOMIDE et al., 2013).

Uma das tecnologias de tratamento de carnes que vem crescendo em todo mundo é a irradiação, porém ainda é pouco difundida no Brasil (SILVA e ROZA, 2010). A irradiação consiste na exposição da carne à radiação ionizante, proveniente tanto de uma máquina de feixes de elétrons como de fontes radioativas (HAM et al., 2017). A radiação gama $(\gamma)$, produzida pelo Cobalto-60 (60Co), tem sido amplamente utilizado não apenas no processo comercial de esterilização de carnes, mas também em pesquisas científicas que determinam mudanças na qualidade da carne irradiada (OLIVEIRA et al., 2009).

A radiação gama tem sido considerada como uma tecnologia promissora para reduzir a intoxicação alimentar induzida por agentes patogénicos e prolongar a vida útil sem comprometer a propriedade nutricional da carne (AYARI et al., 2016), mesmo sob condição de armazenamento não refrigerado (ROBERTS, 2014). Nenhuma substância nociva é gerada e permanece em produtos após a irradiação (SILVA e ROZA, 2010). De acordo com as conclusões do Grupo de Estudo Conjunto Food and Agriculture Organization (FAO), Internatinal Atomic Energy Agengy (IAEA) e Codex Alimentarium, da ONU, os alimentos irradiados em doses adequadas são seguros de consumir e nutricionalmente adequados (WHO, 1999).

Este trabalho apresenta uma revisão sobre a aplicação da radiação gama na conservação de carnes, no que diz respeito à eficiência na redução de microrganismos patogênicos e qualidade destes produtos quando aplicado este método de conservação.

\section{REFERENCIAL TEÓRICO}

\section{$\underline{\text { Legislação }}$}

A legislação brasileira segue as recomendações internacionais sugeridas pela FAO, IAEA e Codex Alimentarium. Atualmente, todas as normas para o emprego desta tecnologia estão descritas na Resolução $\mathrm{n}^{\circ} 21$ da ANVISA (BRASIL, 2001), a qual estabelece que as fontes de radiação utilizadas devem ser as autorizadas pela Comissão Nacional de Energia Nuclear (CNEN). Segundo Brasil (2001), qualquer alimento pode ser irradiado desde que sejam observados os limites mínimos e máximos da dosagem aplicada, sendo que a dose mínima deve ser suficiente para alcançar a finalidade pretendida e a máxima, inferior àquela que comprometeria as propriedades funcionais e/ou atributos sensoriais do alimento.

Os alimentos irradiados oferecidos para consumo devem ser rotulados com o símbolo internacional denominado Radura (Figura 1). O símbolo deve ser acompanhado pelas palavras "tratado por irradiação, não irradiar novamente" ou "tratado com radiação“ (BRASIL, 2001). 


\section{The Journal of Engineering and Exact Sciences -}

JCEC

ISSN: 2527-1075

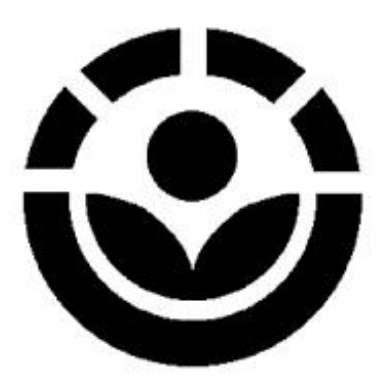

Figura 1: Radura

\section{$\underline{\operatorname{Radiação~} \operatorname{Gama}(\gamma)}$}

A radiação gama é produzida por certos radioisótopos como, por exemplo, Cobalto-60 $(60 \mathrm{Co})$, sendo uma radiação eletromagnética do tipo ionizante. Esse tipo de radiação tem maior potencial de utilização em carnes e derivados cárneos, devido à sua alta penetrabilidade e discreto aumento da temperatura do produto (OLIVEIRA et al., 2009).

A radiação também pode ser usada em combinação com outras técnicas, como a utilização de embalagens, antioxidantes e agentes bioativos, contribuindo para maior estabilidade química e microbiológica do produto ou menor formação de compostos indesejáveis (AYARI et al., 2016; OLIVEIRA et al., 2009). A quantidade de radiação a ser utilizada dependerá do alimento e do objetivo a ser alcançado. Para aplicação em alimentos, a maioria das doses utilizadas se encontram entre 0,1 e 10,0 kGy (MIYAGUSKU et al., 2003).

\section{Conservação de carnes por irradiação}

A radiação gama tem conseguido espaço como ferramenta na redução de patógenos em vários tipos de carnes. Satisfaz plenamente o objetivo de proporcionar nestes alimentos estabilidade nutritiva, condições de sanidade, longo período de armazenamento, além de apresentar característica única de poder ser aplicada em carnes cruas, congeladas ou parcialmente processadas (ROBERTS, 2014). A radiação gama age de duas maneiras sobre os microrganismos: uma produzindo radicais livres oxidativos que promovem danos às membranas celulares e outra provendo a quebra do ácido desoxirribonucleico, causando a paralisação do crescimento de microrganismos (OLIVEIRA et al., 2009).

A irradiação gama foi utilizada com sucesso para controlar a contaminação microbiana em carnes. Fu et al. (1995a) verificaram que a irradiação de dose média (1,8 e 2,0 kGy) em bifes de carne de bovino e carne moída armazenados a $7{ }^{\circ} \mathrm{C}$ por 7 dias destruiu Yersinia enterocolitica e Escherichia coli O157: H7. Fu et al. (1995b) também descobriram que costeletas de porco com doses baixas de radiação $(0,75$ e $0,90 \mathrm{kGy})$ reduziram o número de células viáveis de Listeria monocytogenes em mais de $2 \log$ e de Salmonella typhimurium por 1 e $3 \log$. No mesmo estudo, após a irradiação de dose média (1,8 e 2,0 kGy), populações de patógenos foram reduzidos para níveis indetectáveis. Além disso, os autores demonstraram 


\section{The Journal of Engineering and Exact Sciences - \\ JCEC \\ ISSN: 2527-1075}

que os atributos de qualidade da carne (cor e odor) não foram afetados pela irradiação (FU et al., 1995b).

Badr (2012) verificou que doses de 3 e 1 kGy de radiação gama inativaram 6,59 e 6,05 $\log$ UFC g-1 de Listeria monocytogenes e Vibrio parahaemolyticus, respectivamente, em salmão defumado a frio mantidos sob temperatura de refrigeração de $4 \pm 1{ }^{\circ} \mathrm{C}$ por 42 dias de armazenamento. Além disso, a irradiação diminuiu significativamente as suas populações microbianas de bactérias aeróbias mesofílicas, bactérias anaeróbias, bactérias psicófilas, bactérias de ácido láctico e bolores e leveduras. As enterobacteriaceas foram quase indetectáveis em amostras irradiadas com dose de $2 \mathrm{kGy}$. Os autores observaram que doses com até $3 \mathrm{kGy}$ de irradiação não mostraram efeito significativo sobre a aceitabilidade sensorial dos salmões defumados a frio. Segundo Abreu et al. (2008), amostras de filé de peixe-sapo irradiadas com $5 \mathrm{KGy}$ armazenadas em temperatura de refrigeração por 18 dias obteve melhor qualidade, quanto aos atributos de cor, sabor e aroma, sugerindo uma aparência de maior frescor e a mais eficiente na manutenção da qualidade bacteriológica.

Nos estudos de Kanatt et al. (2005) baixas doses de radiação, entre 2 e 3 KGy , foram efetivas para a redução de Salmonella, E. coli e Staphylococcus ssp. em frangos armazenados à $0-3{ }^{\circ} \mathrm{C}$ por duas semanas. Miyagusku et al. (2003) avaliaram a vida útil de filés de cortes de peito de frangos irradiados e observaram que em doses máximas de 7,0 kGy provocaram sensível redução de Pseudomonas spp, enterobateriaceas e E. coli e bactérias mesófilas aeróbias. A vida útil dos filés de peito mantidos sob refrigeração foi crescente, dependendo da dose de radiação aplicada. Enquanto nas amostras controle a vida útil foi de 5 dias, nas irradiadas estendeu-se por 15, 22 e 32 dias, para doses de 1,5; 3,0 e 7,0 kGy, respectivamente. Oliveira et al. (2009) verificaram que doses de 3,0 kGy foi eficiente na eliminação de Salmonella spp., mesófilos aeróbios estritos e facultativos viáveis, coliformes totais e termotolerantes em peito de frango armazenado à $4^{\circ} \mathrm{C}$ em embalagem convencional ou a vácuo, durante 10 dias de armazenamento. Entretanto, Miyahusku et al. (2003) e Oliveira et al. (2009) verificaram baixa eficiência da radiação gama no controle de bolores e leveduras em carne de frango. Segundo os autores, o fator que pode ter influenciado na alta radiorresistência desses bolores e leveduras é a constituição de sua parede celular, com menor quantidade de ácidos graxos, portanto, menos sensível aos compostos oxidativos formados durante o processo de irradiação.

Apesar da vantagem no controle da contaminação microbiana, tem sido relatado que a irradiação pode afetar negativamente a cor, a estabilidade oxidativa (particularmente a oxidação lipídica) e a palatabilidade sensorial, dependendo do tipo da carne, dos métodos de embalagem e das condições de irradiação (AYARI et al., 2016). A radiação ionizante provoca a radiólise da água que está presente em grande parte na carne. Isto gera radicais livres tais como $\mathrm{OH}$-, elétrons hidratados $\mathrm{e}^{+}$, os quais reagem com o alimento (LACROIX e OUATTARA, 2000). Os lipídios mais afetados durante a irradiação são, portanto, os ácidos graxos poliinsaturados, que possuem duas ou mais ligações duplas. Desta forma, a carne é sensível à deterioração oxidativa, levando à oxidação de ácidos graxos poliinsaturados dos fosfolípidos (HAM et al., 2017). A oximioglobina, de coloração vermelho brilhante, pode ser oxidada a metamoglobina durante o armazenamento, tornando a carne marrom-acinzentada, aspecto que o consumidor rejeita (AYARI et al., 2016). Ham et al. (2017) verificaram que a 


\section{The Journal of Engineering and Exact Sciences - \\ JCEC \\ ISSN: 2527-1075}

oxidação lipídica de amostras de carne bovina e suína foi acelerada pela irradiação independente da dose durante o armazenamento a $30^{\circ} \mathrm{C}$ por 10 dias.

No entanto, a taxa e o nível de deterioração podem ser reduzidos pelo tratamento combinado com antioxidantes e/ou agentes biotivos, que protegem os lípidos da oxidação e estabilizam oximioglobina (AYARI et al., 2016). Ayari et al. (2016) avaliaram os efeitos da radiação gama ( $2 \mathrm{kGy}$ ) na carne moída em combinação com compostos bioativos, consistindo em cinamaldeído e ácido ascórbico. Os resultados demonstraram que os tratamentos com irradiação e compostos bioativos diminuíram significativamente a carga microbiana e não causaram alterações significativas nas propriedades físico-químicas das amostras de carne. $\mathrm{Na}$ presença de ácido ascórbico, o efeito pró-oxidativo do tratamento de irradiação na carne moída foi superado.

\section{CONCLUSÕES}

A radiação gama é eficiente no controle de microrganismos em amostras de carnes, o que garante vida útil prolongada para estes produtos, bem como maior segurança para o consumidor._A utilização de tratamento combinado com irradiação tem efeito sinérgico capazes de eliminar as bactérias patogênicas e reduzir a taxa de oxidação de ácidos graxos poliinsaturados.

\section{REFERÊNCIAS}

ABREU, M. G.; FREITAS, M. Q.; JESUS, E. F. O.; SÃO CLEMENTE, S. C.; FRANCO, R. M.; BORGES, A. Caracterização sensorial e análise bacteriológica do peixe-sapo (Lophius gastrophysus) refrigerado e irradiado. Ciência Rural, Santa Maria, v. 38, n. 2, p. 498-503, 2008.

AYARI, S.; HAN, J.; DANG VU, K.; LACROIX, M. Effects of gamma radiation, individually and in combination with bioactive agents, on microbiological and physicochemical properties of ground beef. Food Control, Oxford, n. 1, v. 64, p. 173$180,2016$.

BADR, H. M. Control of the potential health hazards of smoked fish by gamma irradiation. International Journal of Food Microbiology, Amsterdam, v. 154, n. 3, p. 177-186, 2012.

BRASIL. Agência Nacional de Vigilância Sanitária. Resolução RDC no 21, de 26 de janeiro de 2001. Aprova o Regulamento Técnico para Irradiação de Alimentos. Diário Oficial [da] República Federativa do Brasil, Poder Executivo, Brasília, 2001.

FU, A. -H.; SEBRANEK, J. G.; MURANO, E. A. Survival of Listeria monocytogenes, Yersinia enterocolitica and Escherichia coli O157:H7 and quality changes after irradiation of beef steaks and ground beef. Journal of Food Science, Chicago, v. 60, n. 5, p. 972-977, 1995a.

FU, A.-H.; SEBRANEK, J. G.; MURANO, E. A. Survival of Listeria monocytogenes and Salmonella typhimurium and quality attributes of cooked pork shops and cured ham after irradiation. Journal of Food Science, Chicago, v. 60, n. 5, p. 1001-1005, 1995 b.

GOMIDE, L. A. M.; RAMOS, E. M.; FONTES, P. R. Ciência e qualidade da carne: fundamentos. 1 ed. Viçosa: UFV, 2013. 197 p. 
HAM, Y. K; KIM, H. W.; HWANG, K. E.; SONG, D. H.; KIM, Y. J.; CHOI, Y. S.; SONG, B. S.; PARK, J. H.; KIM, C. J. Effects of irradiation source and dose level on quality characteristics of processed meat products. Radiation Physics and Chemistry, Oxford, v. 130, n. 1, p. 259-264, 2017.

KANATT, S. R.; CHANDER, R.; SHARMA, A. Effect of radiation processing on the quality of chilled meat products. Meat Science, Barking, v. 69, n. 2, p. 269-275, 2005.

LACROIX, M., OUATTARA, B. Combined industrial processes with irradiation to

assure innocuity and preservation of food products - a review. Food Research International, Kidlington, v. 33, n. 9, p. 719-724, 2000.

MIYAGUSKU, L.; CHEN, F.; LEITÃO, M. F. F.; BAFFA, O. Avaliação microbiológica e sensorial da vida-útil de cortes de peito de frango irradiados. Ciência e Tecnologia de Alimentos, Campinas, v. 23, n. 7-16, p. 7-16, 2003.

OLIVEIRA, A. L.; PEREIRA, M. T.; BUENO, P. H. S.; OLIVEIRA, R. B. P.; PINTO, F. C.; CORREIA, R. F.; MACHADO, M. M. Qualidade microbiologica da carne de frango irradiada em embalagem convencional e a vácuo. Arquivo Brasileiro de Medicina Veterinária e Zootecnia, Belo Horizonte, v. 61, n. 5, p. 1210-1217, 2009.

ROBERTS, P. B. Food irradiation: Standards, regulations and world-wide trade. Radiation Physics and Chemistry, Oxford, v. 129, n. 1, p. 30-34, 2016.

SILVA, A. L. F.; ROZA, C. R. Uso da irradiação em alimentos: revisão. B. CEPPA, Curitiba, v. 28, n. 1, p. $49-56,2010$.

WHO. World Health Organization. High-dose irradiation: wholesomeness of food irradiated with doses above $10 \mathrm{kgy}$. Report of a Joint FAO/IAEA/WHO Study Group. World Health Organization, Geneva. 1999. 